\title{
Increase of in-Hospital Mortality of Stemi- Patients After PCI? A Risk Adjusted Analysis of German Quality Assurance Data 2008 -2013
}

\author{
Bestehorn $\mathrm{K}^{1 *}$, Bestehorn $\mathrm{M}^{2}$, Fleck $\mathrm{E}^{3}$, D`Ancona $\mathrm{G}^{4}$, Ince $\mathrm{H}^{5}$ and Eggebrecht $\mathrm{H}^{6}$ \\ ${ }^{1}$ Technical University Dresden, Germany \\ ${ }^{2}$ ProMedCon GmbH, Ebenhausen, Germany \\ ${ }^{3}$ German Cardiac Society, Berlin, Germany \\ ${ }^{4}$ Vivantes Hospital Berlin, Germany \\ ${ }^{5}$ Department of Cardiology, Rostock University Center, Germany \\ ${ }^{6}$ Cardioangiological Center Bethanien, Germany
}

Submission: March 08, 2019; Published: March 21, 2019

*Corresponding author: Bestehorn Kurt, Institute of Clinical Pharmacology, TU Dresden Fiedlerstr. 46, D-01307 Dresden, Germany

Keywords: Myocardial infarction; Percutaneous coronary intervention; Coronary artery; Coronary angiography; In-hospital mortality; Procedure complications

Abbrevations: STEMI: ST Elevation Myocardial Infarction; PCI: Percutaneous Coronary Interventions; CABG: Coronary Artery Bypass Graft Surgery; EF: Ejection Fraction; CS: Cardiogenic Shock

\section{Introduction}

In-hospital mortality (IHM) of patients presenting with acute ST Elevation Myocardial Infarction (STEMI) is one of the most important quality indicators. Despite recent advances in Percutaneous Coronary Interventions (PCI) (better stents, higher rates of transradial PCI, area wide access to 24 hour/7days a week), the compulsory German quality assurance reports have shown a steady increase in unadjusted IHM after PCI for STEMI from 2008 to $2013: 6.7 \%-7.1 \%-7.4 \%-7.8 \%-8.3 \%-8.7 \%$ [1-4]. In the present paper we have therefore analyzed results of all patients undergoing acute PCI for STEMI in Germany in 2008 and 2013. Starting from the compulsory German Quality Assurance Registry datasets, we have focused upon a risk-adjusted approach to evaluate if the observed increase in mortality indeed reflects worse performance of cath-lab teams or is actually secondary to a higher risk profile of the patients undergoing PCI for STEMI.

\section{Methods}

\section{Patients}

The 2008 and 2013 PCI datasets of the German Federal Council, held by the AQUA institute (Göttingen, Germany), were analyzed. Registry participation and data collection were compulsory and comprises all in-patient procedures performed in German hospitals. The quality of the dataset was controlled by a validated system including testing for plausibility and correctness and, in case of statistical outliers, by structured interviews. Details of the AQUA PCI registry have been described in detail previously [5]. The dataset contains parameters such as baseline clinical characteristics, risk factors/comorbidities, procedural information, intra-and post-procedural events, and inhospital clinical outcomes. For the present analysis, only patients primarily hospitalized in cardiac departments with a diagnosis of STEMI and confirmed coronary artery disease requiring primary PCI were included.

Patients who were initially admitted to non-cardiac departments were excluded from the analysis mainly to minimize the impact of non-cardiac comorbidities upon IHM of primary PCI for STEMI. Finally, patients referred to urgent heart surgery after coronary angiography/PCI and patients with incomplete data were excluded from the analysis.

\section{Statistical methods}

The primary endpoint of our analysis was to document that IHM rate was equivalent in 2013 and 2008. We assumed a 
difference not greater than $\pm 1 \%$ between the two IHM rates. An equivalence test for IHM was conducted as recommended in Methods for Equivalence and Non-inferiority Testing [6].

The equivalence hypotheses are

$$
\begin{aligned}
& \mathrm{H}_{0}: \mathrm{D}=\left|\mathrm{IHM}_{2008}-\mathrm{IHM}_{2013}\right| \geq 0.01 \\
& \mathrm{H}_{\mathrm{A}}: \mathrm{D}=\left|\mathrm{IHM}_{2008}-\mathrm{IHM}_{2013}\right|<0.01
\end{aligned}
$$

where $\mathrm{IHM}_{2008}$ is the in-hospital mortality for 2008 and IHM $_{2013}$ is the in-hospital mortality for 2013. In a first step the 2 cohorts from 2008 and 2013 were compared. In a second step a risk-/condition-vector was defined for each patient comprising the following variables: age, sex, previous diagnostic coronary angiography, previous catheter intervention, previous Coronary Artery Bypass Graft Surgery (CABG), diabetes mellitus, left ventricular ejection fraction (EF), clinically apparent heart failure, renal insufficiency with or without dialysis, cardiomyopathy, aortic aneurysm, valvular heart disease, hypertensive heart disease, coronary stenosis $>50 \%$, other cardiac diseases, PCI targets (i.e. number of vessels, PCI at unprotected vessel/unprotected main stem/completely occluded vessel/last remaining vessel, PCI at ostium, PCI at bypass vessel), reanimation before procedure, intraprocedural events (vessel occlusion, transitory ischemic attack, reanimation), 2-vessel PCI, 3-vessel PCI, implantation of stent(s), and cardiogenic shock at time of procedure. Patient-clusters with exactly the same risk-/condition vector were identified for 1:1 analysis of exact matchings. The IHMs for the 2008 or 2013 cohort of all possible 1:1 matching converged to the result of a minimum weighting of the clusters. The method, including its mathematical bases has been previously described [7]. The IHMs of the resulting cohorts from 2008 and 2013 with identical risk factor profile were calculated. In addition to the matching, a regression model (binary logistic) was built using the above-mentioned variables. This model was applied to the 2013 data to estimate the IHM of 2013 with the risk adjustment of 2008. While the matching compares cohorts of cases with exactly the same risk profile, but uses only two thirds of the available data, the regression model uses all data, but has an inherent uncertainty as this is only an estimation of IHM. Results are presented as mean \pm standard deviation for baseline continuous variables. Categorical variables, IHM, intra- and post-procedural events are given as rates. The statistical analysis was performed in cooperation with the AQUA Institute using IBM SPSS for Windows Version 24.0. A p value of 0.05 was considered significant.

\section{Results}

\section{Unadjusted overall patient cohorts}

The number of patients undergoing PCI for acute STEMI increased from 15.642 in 2008 to 18.241 in 2013 ( $\mathrm{p}<0.001)$. Baseline parameters and risk factors of the 2 cohorts are presented in Table 1. Patients undergoing PCI in 2013 were older and had a more complex risk profile than patients treated 2008. Gender distribution and incidence of diabetes mellitus were not significantly different in 2008 and 2013.There was a statistically significant increase in patients with cardiogenic shock, $\mathrm{EF}<40 \%$, chronic heart failure, and renal failure at time of procedure. With respect to technical characteristics of the primary PCI procedure an increase towards more complex and high risk procedures like PCI of unprotected vessel/unprotected main stem/ completely occluded vessel/last remaining vessel, PCI of bypass grafts was noted $(58.7 \%$ in 2008 and $60.7 \%$ in 2013; p<0.001). PCI of occluded vessels was the most frequent indication for revascularization (Table 1 ). For both cohorts the rates of serious complications (i.e. TIA/stroke, occlusion of coronary vessel, resuscitation) was low. Nevertheless, an increase of overall intra-procedural complications was noted in 2013 as compared to 2008 : $8.7 \%$ vs. $7.6 \%$, p $<0.001$ (Table 2). Rates of overall postprocedural complications increased by $1.2 \%$, a relative increase of approximately $16 \%$ of the observed rate of $7.6 \%$ (Table 3 ). Unadjusted IHM as primary endpoint of this analysis increased from $5.9 \%$ in 2008 to $7.3 \%$ in 2013 ( $\mathrm{p}<0.001)$. IHM in men was $5.0 \%(2008)$ and $6.3 \%(2013)(\mathrm{p}<0.001)$, in women $8.2 \%(2008)$ and $10.0 \%$ (2013) $(\mathrm{p}<0.001)$.

Table 1: baseline data.

\begin{tabular}{|c|c|c|c|}
\hline Parameter & $\begin{array}{c}\text { STEMI 2008 } \\
\text { (n=15.642) }\end{array}$ & $\begin{array}{c}\text { STEMI 2013 } \\
\text { (n=18.241) }\end{array}$ & p value \\
\hline $\begin{array}{c}\text { Age (average i. years, } \\
\text { SD) }\end{array}$ & $63.5 \pm 12.9$ & $63.9 \pm 13.2$ & 0.005 \\
\hline Age > 80 years (\%) & 9.7 & 11.7 & $<0.001$ \\
\hline Sex (female, \%) & 28.1 & 27.4 & 0.169 \\
\hline Diabetes mellitus (\%) & 19.4 & 18.9 & 0.295 \\
\hline EF < 40\% (\%) & 13.9 & 18.0 & $<0.001$ \\
\hline Prior CABG (\%) & 3.8 & 3.3 & 0.007 \\
\hline $\begin{array}{c}\text { Renal insufficiency not } \\
\text { dialysis dependent (\%) }\end{array}$ & 13.3 & 16.3 & $<0.001$ \\
\hline $\begin{array}{c}\text { Prior diagnostic CA } \\
\text { (\%) }\end{array}$ & 20.5 & 20.1 & 0.434 \\
\hline $\begin{array}{c}\text { Prior Resuscitation } \\
\text { (\%) }\end{array}$ & 0.2 & 0.2 & 0.398 \\
\hline $\begin{array}{c}\text { Cardiac insufficiency } \\
\text { (\%) }\end{array}$ & 15.6 & 17.6 & $<0.001$ \\
\hline $\begin{array}{c}\text { Cardiogenic shock at } \\
\text { time of procedure (\%) }\end{array}$ & 6.1 & 7.2 & $<0.001$ \\
\hline \begin{tabular}{c} 
PCI at 2 vessels (\%) \\
\hline $\begin{array}{c}\text { PCI at occluded vessel } \\
\text { (\%) }\end{array}$
\end{tabular} & 8.4 & 8.5 & 0.014 \\
\hline
\end{tabular}

(SD: Standard Deviation, EF: Ejection Fraction, CABG: Coronary Artery Bypass Grafting, CA: Coronary Angiography, PCl: Percutaneous Coronary Intervention)

Table 2: intra-procedural events (overall and selected specific events).

\begin{tabular}{|c|c|c|c|}
\hline $\begin{array}{c}\text { Intra-proce- } \\
\text { dural event }\end{array}$ & $\begin{array}{c}\text { STEMI 2008 } \\
(\mathbf{n = 1 5 . 6 4 2 )}\end{array}$ & $\begin{array}{c}\text { STEMI 2013 } \\
(\mathbf{n = 1 8 . 4 2 1 )}\end{array}$ & $\mathbf{p}$ \\
\hline Overall (\%) & 7.6 & 8.7 & 0.001 \\
\hline $\begin{array}{c}\text { Resuscitation } \\
(\%)\end{array}$ & 1.4 & 2.3 & 0.001 \\
\hline TIA /stroke (\%) & 0.05 & 0.1 & 0.1189 \\
\hline
\end{tabular}

(TIA: transient ischemic attack) 
Table 3: Unadjusted overall cohort: post-procedural events (overall and selected specific events).

\begin{tabular}{|c|c|c|c|}
\hline $\begin{array}{c}\text { Post-procedural } \\
\text { event }\end{array}$ & $\begin{array}{c}\text { STEMI 2008 } \\
(\mathrm{n}=15.642)\end{array}$ & $\begin{array}{c}\text { STEMI 2013 } \\
(\mathrm{n}=18.421)\end{array}$ & $\mathrm{p}$ \\
\hline Overall (\%) & 7.6 & 8.8 & $<0.001$ \\
\hline Repeat MI (\%) & 0.6 & 0.3 & $<0.001$ \\
\hline $\begin{array}{c}\text { MI <36 h past } \\
\text { procedure (\%) }\end{array}$ & 0.3 & 0.2 & $<0.001$ \\
\hline $\begin{array}{c}\text { MI >36 h past } \\
\text { procedure (\%) }\end{array}$ & 0.3 & 0.1 & $<0.001$ \\
\hline $\begin{array}{c}\text { TIA / stroke } \\
\text { (\%) }\end{array}$ & 0.1 & 0.1 & 0.086 \\
\hline $\begin{array}{c}\text { Resuscitation } \\
\text { (\%) }\end{array}$ & 0.9 & 1.3 & $<0.002$ \\
\hline
\end{tabular}

(MI: myocardial infarction, TIA: transient ischemic attack)

\section{Risk adjusted analysis}

Supplement Table 1: Basic and intra-procedural parameters of the matched cohorts.

\begin{tabular}{|c|c|c|c|c|}
\hline Parameter & $\begin{array}{c}\text { STEMI } \\
\mathbf{2 0 0 8} \\
(\mathbf{n = 8 , 9 7 9 )}\end{array}$ & $\begin{array}{c}\text { STEMI } \\
\mathbf{2 0 1 3} \\
\text { (n=8,979) }\end{array}$ & P value & $\begin{array}{c}\text { Stan- } \\
\text { dard } \\
\text { differ- } \\
\text { ence }\end{array}$ \\
\hline Age (average i. years) & 61.9 & 61.9 & 1 & 0 \\
\hline Males (\%) & 76.3 & 76.3 & 1 & 0 \\
\hline EF < 40\% (\%) & 5.5 & 5.5 & 1 & 0 \\
\hline Prior CABG (\%) & 0.3 & 0.3 & 1 & 0 \\
\hline $\begin{array}{c}\text { Renal insufficiency } \\
\text { not dialysis depen- } \\
\text { dent (\%) }\end{array}$ & 6.8 & 6.8 & 1 & 0 \\
\hline Diabetes mellitus (\%) & 11.1 & 11.1 & 1 & 0 \\
\hline PCI at one vessel (\%) & 96.6 & 96.6 & 1 & 0 \\
\hline PCI at 2 vessels (\%) & 3.4 & 3.4 & 1 & 0 \\
\hline $\begin{array}{c}\text { PCI at occluded } \\
\text { vessel (\%) }\end{array}$ & 52.9 & 52.9 & 1 & 0 \\
\hline PCI at ostium (\%) & 1.2 & 1.2 & 1 & 0 \\
\hline $\begin{array}{c}\text { Prior diagnostic CA } \\
\text { (\%) }\end{array}$ & 9.3 & 9.3 & 1 & 0 \\
\hline $\begin{array}{c}\text { Cardiac insufficiency } \\
\text { (\%) }\end{array}$ & 5.0 & 5.0 & 1 & 0 \\
\hline Cardiomyopathy (\%) & 0.2 & 0.2 & 1 & 0 \\
\hline $\begin{array}{c}\text { Other cardiac diseas- } \\
\text { es /\%) }\end{array}$ & 2.0 & 2.0 & 1 & 0 \\
\hline $\begin{array}{c}\text { Resuscitation before } \\
\text { procedure (\%) }\end{array}$ & 0.1 & 0.1 & 1 & 0 \\
\hline $\begin{array}{c}\text { Cardiogenic shock } \\
\text { at time of procedure } \\
\text { (\%) }\end{array}$ & 1.5 & 1.5 & 1 & 0 \\
\hline
\end{tabular}

(EF: ejection fraction, CABG: coronary artery bypass graft surgery, $\mathrm{PCl}$ : percutaneous coronary intervention, CA: coronary angiograph)

Exact matching resulted in 2 cohorts of 8.979 patients in each group (Supplement Table 1). As result of the matching method patients in each group had an identical risk factor profile. Use of drug-eluting stents use increased from $17.2 \%$ in 2008 to $77.4 \%$ in $2013(\mathrm{p}<0.001)$, as well as the proportion of cases receiving more than 3 stents during the procedure $(2.9 \%$ vs. $10.7 \%(p<0.001))$. Rates of risk-adjusted IHM were not different between 2008 and 2013 (2.3\% vs. $2.6 \%, \mathrm{p}=0.244$ ). Equivalence testing yielded equivalent rates of IHM in 2008 and 2013 within an interval of $\pm 1 \%$ (p-values: 0.002 and $<0.001$ ). Rates of overall postprocedural events were $4.3 \%$ for both 2008 and 2013 and thus not different $(\mathrm{p}=0.941)$. There were no differences in MI, TIA/stroke, pulmonary embolism, resuscitation, revision, or complications at puncture site. The results of the regression model analysis (based on the 2008 data but applied to the 2013 data) are shown in Table 4. There was no difference between observed and expected IHM $(\mathrm{p}=0.466)$ confirming the results of the matched-pair analysis. Again, equivalence testing yielded equivalent rates of IHM in 2008 and 2013 within an interval of $\pm 1 \%$ (p-values: 0.003 and $<0.001$ ).

Table 4: Regression model results

\begin{tabular}{|c|c|c|}
\hline & 2013 observed & 2013 expected \\
\hline alive & 16,911 & 16,497 \\
\hline IHM $\mathrm{n}(\%)$ & $1,330(7.3)$ & $1,294(7.1)$ \\
\hline total & 18,241 & 18,241 \\
\hline
\end{tabular}

(IHM: intra-hospital mortality)

\section{Discussion}

Three main findings are emerging from our analysis: 1). In Germany unadjusted IHM after primary PCI for STEMI has increased from 2008 (5.9\%) to 2013 (7.3\%, p<0.001 vs. 2008). 2) With improved operators' confidence and routine of acute PCI, more and even older and sicker (higher-risk) patients have been treated with primary PCI in 2013, a group which was previously excluded from this life-saving therapy. Also, more complex coronary procedures were performed during primary PCI.3) Finally and most importantly analysis of risk adjusted IHM revealed no differences in IHM between 2008 and 2013 (2.3\% v. $2.7 \%, \mathrm{p}=0.244$ ), which was confirmed by regression model analysis.

In contrast to observations reporting a decreasing IHM after primary PCI for STEMI from 1990 to 2008 [8-12] our findings - in unadjusted patients cohorts - are in accordance with the National Cardiovascular Data Registry (NCDR) Cath PCI Registry [13]. Despite shortened door-to-balloon time, the NCDR has similarly shown increasing IHM between 2005 and 2011 in a growing and changing population of patients undergoing primary PCI. The Nationwide Inpatient Sample (NIS) database [14] has reported a decrease of IHM following myocardial infarction from 2003 to 2009 (9.49 to $7.17 \%$ ) but an increase thereafter ( $8.25 \%$ in 2011). Both analyses showed-similar to our results higher baseline risk of more comorbid patients undergoing primary PCI, explaining higher rate of observed IHM. In the NIS registry adjusted OR for IHM increased from 2.74 (2008) to 4.16 (2011) together with an increase of co-morbidities (i.e. diabetes, hypertension). In our analysis the percentage of elderly patients ( $>75$ years) increased from $9.7 \%$ to $11.7 \%$ in 2008 and 2013 respectively. An increased age, per se, is related to a higher IHM in patients presenting with ACS [16]. Similarly, the percentage of patients 
presenting with renal insufficiency as risk factor of IHM [17] has increased from $13.3 \%$ to $16.3 \%$. Cardiogenic Shock (CS) is one of the most important reasons for IHM in patients with STEMI [18-19]. Wayangankar et al. [15] hypothesized that IHM in MI patients with cardiogenic shock who are managed invasively is decreasing with improved use of timely revascularization, mechanical ventricular support, and advanced medical treatment. But despite the evolution of medical technology and use of contemporary therapeutic measures, they found that IHM in CSAMI patients who are managed by PCI continued to rise from $27.6 \%$ in 2005 to $30.6 \%$ in 2013 . In our data this is reflected by an increased resuscitation rate in CS patients referred for primary PCI in STEMI. Although direct measurements of the impact of a worsened risk profile is challenging, we have estimated that up to $0.4 \%$ of the annual increase of $1.4 \%$ of IHM may be attributable to the increased reanimation rate observed in patients presenting in cardiogenic shock at time of referral for PCI (data not shown). In fact, the continuous amelioration of some structural and logistical components of the health care system (e.g. improved patient transportation, increased availability/capacity of catheter labs and reduced distance to catheter labs all leading to a shortening of the pre-hospitalization period) may have resulted in an increased number of highly comorbid patients at increased risk for IHMthat actually reach the hospital alive and are candidates for PCI treatment of STEMI.

\section{Limitations}

Our analysis has several limitations. The dataset structure has allowed us to analyze only the rates of IHM. Moreover, our analysis is confined to the in-hospital period while longer-term follow-up is not captured in the registry. Incompleteness of the submitted data, which is inherent to all observational registry data, cannot be excluded, especially as events are reported without routine on-site data verification. In any case, the primary endpoint of our analysis has been IHM, which by nature should be valid. Finally, the number of co-morbidities and additional pre-procedural information documented in the database is limited. Therefore, possible and additional confounding factors such as comorbidities like chronic obstructive airways disease, hypertension, anemia, rheumatic disease, and socioeconomic status or even nutritional status [20], which may have an important impact upon IHM, are not available. The same is true for laboratory parameters like biomarker levels [21,22] and pre-procedural pharmacological management. Moreover, evaluation of experience and skills of the treating physician/team, both strictly related to IHM, was not available in the used dataset.

\section{Conclusion}

The increase of IHM rate after primary PCI for STEMI during the years 2008 and 2013 can be mostly explained by an increased pre-procedural risk profile of the referred patients. This is supported by the fact that, after risk adjustment, exact matching analysis has shown no statistically significant differences in IHM.

\section{Conflict of interest}

On behalf of all authors, the corresponding author states that there is no conflict of interest.

\section{References}

1. Zeymer U, Hochadel M, Zahn R, Kuck KH, Brachmann J, et al. (2012) Indikationen zur Koronarangiographie und perkutanen koronaren Intervention (PCI) in Deutschland von 2004 bis 2009. Kardiologe 6(5): 390-398.

2. Deutsche Herzstiftung (2014) Deutscher Herzbericht 2014. Frankfurt am Main, Germany.

3. (2013) AQUA - Institut für angewandte Qualitätsförderung und Forschung im Gesundheitswesen. Qualitätsbericht 2012. Göttingen, Germany.

4. Macher-Heidrich S. 6. (2014) Qualitätssicherungskonferenz Externe stationäre Qualitätssicherung Koronarangiographie und PCI (21/3).

5. Eggebrecht H, Mehta RH (2016) Transcatheter aortic valve implantation (TAVI) in Germany 2008-2014: on its way to standard therapy for aortic valve stenosis in the elderly? Eurointervention 11(9): 1029-1033.

6. Tunes da Silva G, Logan BR, Klein JP (2008) Methods for Equivalence and Non-inferiority Testing. Biol Blood Marrow Transplant 15(1 Suppl): 120-127.

7. Bestehorn F et al. (2018) A finest balancing score algorithm to avoid common pitfalls of propensity score matching. arXiv:1803.02704 2018.

8. Peterson D, Shah BR, Parsons L, Pollack CV, French WJ, et al. (2008) Trends in quality of care for patients with acute myocardial infarction in the National Registry of Myocardial Infarction from 1990 to 2006. Am Heart J 156(6): 1045-1055.

9. Rogers WJ, Frederick PD, Stoehr E, Canto JG, Ornato JP, et al. (2008) Trends in presenting characteristics and hospital mortality among patients with ST elevation and non-ST elevation myocardial infarction in the National Registry of Myocardial Infarction from 1990 to 2006. Am Heart J 156(6): 1026-1034.

10. Yeh RW, Sidney S, Chandra M, Sorel M, Selby JV, et al. (2010) Population Trends in the Incidence and Outcomes of Acute Myocardial Infarction. N Engl J Med 362(23): 2155-2165.

11. Sugiyama T, Hasegawa K, Kobayashi Y, Takahashi O, Fukui T, et al. (2015) Differential Time Trends of Outcomes and Costs of Care for Acute Myocardial Infarction Hospitalizations by ST Elevation and Type of Intervention in the United States, 2001-2011. J Am Heart Assoc 4(3): e001445.

12. Toma A, Stähli BE, Gick M, Ferenc M, Mashayekhi K, et al. (2018) Temporal changes in outcomes of women and men undergoing percutaneous coronary intervention for chronic total occlusion: 20052013. Clin Res Cardiol 107(6): 449-459.

13. Nallamothu KJ, Normand S-LT, Wang Y, Hofer TP, Brush Jr JE, et al. (2015) Relation between door-to-balloon times and mortality after primary percutaneous coronary intervention over time: a retrospective study. Lancet 385(9973): 1114-1122.

14. Shah RU, Henry TD, Rutten-Ramos S, Garberich RF, Tighiouart M, et al. (2015) Increasing Percutaneous Coronary Interventions for STSegment Elevation Myocardial Infarction in the United States: progress and opportunity. JACC Cardiovasc Interv 8(1 Pt B): 139-146.

15. Wayangankar SA, Bangalore S, McCoy LA, Jneid H, Latif F, et al. (2016) Temporal Trends and Outcomes of Patients Undergoing Percutaneous Coronary Interventions for Cardiogenic Shock in the Setting of Acute 
Myocardial Infarction. A Report From the CathPCI Registry. JACC Cardiovasc Interv 9 (4): 341-351.

16. Bauer T, Möllmann H, Weidinger F, Zeymer U, Seabra-Gomes R, et al. (2011) Predictors of hospital mortality in the elderly undergoing percutaneous coronary intervention for acute coronary syndromes and stable angina. Int J Cardiol 151(2): 164-169.

17. Stähli BE, Gebhard C, Gick M, Ferenc M, Mashayekhi K, et al. (2018) Outcomes after percutaneous coronary intervention for chronic total occlusion according to baseline renal function. Clin Res Cardiol 107(3): 259-267.

18. Kolte D, Khera S, Aronow WS, Mujib M, Palaniswamy C, et al. (2014) Trends in Incidence, Management, and Outcomes of Cardiogenic Shock Complicating ST-Elevation Myocardial Infarction in the United States. J Am Heart Assoc 3(1): e000590.

19. Backhaus T, Fach A, Schmucker J, Fiehn E, Garstka D, et al. (2018) Management and predictors of outcome in unselected patients with cardiogenic shock complicating acute ST-segment elevation myocardial infarction: results from the Bremen STEMI Registry. Clin Res Cardiol 107(5): 371-379.

20. Wada H, Dohi T, Miyauchi K, Doi S, Konishi H, et al. (2017) Prognostic impact of nutritional status assessed by the Controlling Nutritional Status score in patients with stable coronary artery disease undergoing percutaneous coronary intervention. Clin Res Cardiol 106(11): 875883.

21. Plakht Y, Gilutz H, Shiyovich A (2018) Sodium levels during hospitalization with acute myocardial infarction are markers of inhospital mortality: Soroka acute myocardial infarction II (SAMI-II) project. Clin Res Cardiol 107(10): 956-964.

22. Leibundgut G, Gick M, Morel O, Ferenc M, Werner KD, et al. (2016) Discordant cardiac biomarker levels independently predict outcome in ST-segment elevation myocardial infarction. Clin Res Cardiol 105(5): $432-440$.

Your next submission with Juniper Publishers
will reach you the below assets
- Quality Editorial service
- Swift Peer Review
- Reprints availability
- E-prints Service
- Manuscript Podcast for convenient understanding
- Global attainment for your research
- Manuscript accessibility in different formats
( Pdf, E-pub, Full Text, Audio)
Unceasing customer service
Track the below URL for one-step submission
https://juniperpublishers.com/online-submission.php

